\title{
Optimization of a large horizontal-axis wind turbine using comparison between two hybrid evolutionary algorithms
}

\author{
Ehsanolah Assareh ${ }^{\mathrm{a}}$ And Mojtaba Biglari \\ Faculty of Mechanical Engineering, Semnan University, P.O. Box: 35131-19111, Semnan, Iran
}

Received 11 August 2015, Accepted 2 December 2015

\begin{abstract}
Twist and chord distribution are important parameters in optimal blade shape of MW class wind turbines. Although this is a serious challenge for the designer, their optimum design is an imperative for success in reaching the optimal blade shape. In this regard, the use of a suitable tool can be very effective in achieving this important goal. Furthermore, in order to improve the performance of large wind turbines, an objective function involving the combination of parameters of solidity and power coefficients are provided. The output power of the wind turbine is presented as the power coefficient of this objective function. Based on the presented objective function, it is sought to maximize power generation and minimize solidity. A decrease in solidity can cause weight loss of blades and ultimately reduce costs and consumed materials. One of the useful skills in solving optimization problems with high accuracy and convergence rate is hybridization of intelligent optimization algorithms. In this paper, we provided a comparison between two hybrid Evolutionary algorithm methods as genetic-based bees algorithm (GBBA) and harmony searchbased bat algorithm (HSBBATA) optimization algorithms for designing the optimum shape of MW wind turbine blades. The present paper introduces two hybrid algorithms called HSBBAT and GBBA. GBBA is a novel population-based hybrid algorithm (proposed method). Therefore; we have tried using the hybrid algorithms to achieve better results for finding global optimum points with higher power generation and convergence rate for optimal blade shape of large wind turbines. On the other hand, defining three different scenarios for twist and chord, it is intended to achieve an optimal distribution for these aerodynamic parameters. The results show that the suggested algorithm GBBA, proves to have better results compared to HSBBATA.
\end{abstract}

Key words: Blade design / optimization / harmony search-based bat algorithm (HSBBATA) / geneticbased bees algorithm (GBBA) / MW class wind turbine

\section{Introduction}

One of the most important issues in the history of mankind has been the issue of energy. With the advancement of technology and science in the past decade, energy consumption has greatly increased. Experts believe that the consumption of electricity until the year 2035 will increase two-fold compared with 2008. Nowadays, due to the pollution caused by fossil fuels, global warming and indiscriminate increase in fuel prices, the use of fossil fuels resources is limited. As a result, a source of renewable energy around the world is one of the main topics for researchers. Wind energy is one of the renewable energy sources that have received special attention in many countries due to its purity and cost-effectiveness [1]. Wind turbines are the most important tools for the production of energy from wind, thus optimizing the turbines is an im-

a Corresponding author: E.Assareh@Semnan.ac.ir portant issue [2]. One of the most important components in the optimization process of the performance of large wind turbines is their blades. The main purpose of the design and optimization of blades in large wind turbines is to maximize their output power. In this paper, considering the importance of effective aerodynamic parameters for designing the blade such as chord and twist, it is tried to achieve a reasonable distribution using mathematical modeling of the behavior of the blades (BEM) and intelligent optimization algorithms. Therefore, presenting three different scenarios in this article, it is sought to achieve the best distribution of twist and chord. Numerous studies have been conducted on optimized distribution of twist and chord for wind turbines blades; these include [3-7]. In this article, it is aimed to achieve better results for these distributions by applying various mathematical functions and using artificial neural networks as useful tools. One of the main aspects of the current paper is the issue of 
optimization and finding the optimal shape of blades for large wind turbines. Therefore, by introducing a new algorithm, it is attempted to achieve optimal results along with high-speed convergence. Hybridizing intelligent algorithms and exploiting the advantages of these algorithms to make a new hybrid algorithm is one of the helpful methods in achieving better results in different engineering problems. The current study aimed to compare the two hybrid methods of GBBA and HSBBA in the optimization of power generation in wind turbines. The GA and the BA algorithms were mixed to make the hybrid GBBA, and the HS and the BAT algorithms were mixed to make the hybrid HSBBA. Hybrid methods have been used in a large number of studies dealing with different engineering problems [8-11], but it is the first time that these methods are employed in this field. In this study, by considering an objective function as a combination of output power and solidity, the design of blade of large wind turbines was investigated in more details. Needless to say, in addition to the importance of maximizing output power in the design of blades, other parameters, such as solidity, can also be effective in improving the performance of this design. Applying solidity as a part of the objective function with a minimizing approach helps the designer to design a turbine with lower costs, lower consumption of materials and better performance. Several research studies have been done in this area such as $[1,7]$ in which in addition to the output power parameter, other factors have also been examined.

This article includes 15 sections. In Section 1, an introduction is given. In Section 2, the aerodynamic design of wind turbines blades was mentioned. In Section 3, the Annual Energy Production (AEP) is analyzed. In Section 4, the characteristics of the initial wind turbine used in this article was mentioned. In Section 5, wind turbine blade design parameters are analyzed. Section 6 provides details about mathematical modeling of the rotor performance. Sections 7, 8, 9, and 10 present ANN, GA, BA, and GBBA algorithms, respectively. In Sections 11, 12 and 13 the objective function, determination of the appropriate weighting factor and design constraints are discussed. Section 14 provides details about the valuating of the work. In Section 15, t he optimization process of wind turbine blade is studied. Finally, in Section 16, the conclusion and future works are explained.

\section{Aerodynamic design of wind turbine}

\subsection{The momentum theory}

Figure 1 demonstrates a one-dimensional tube in which the wind turbine rotor is considered as an actuator disk.

Such an actuator disk is effective in that it brings about a step drop in pressure and at the same time allows maintaining a constant speed at the rotor area. The momentum theory considers the wind turbine rotor as an actuator disk which makes the rotor blades receive a

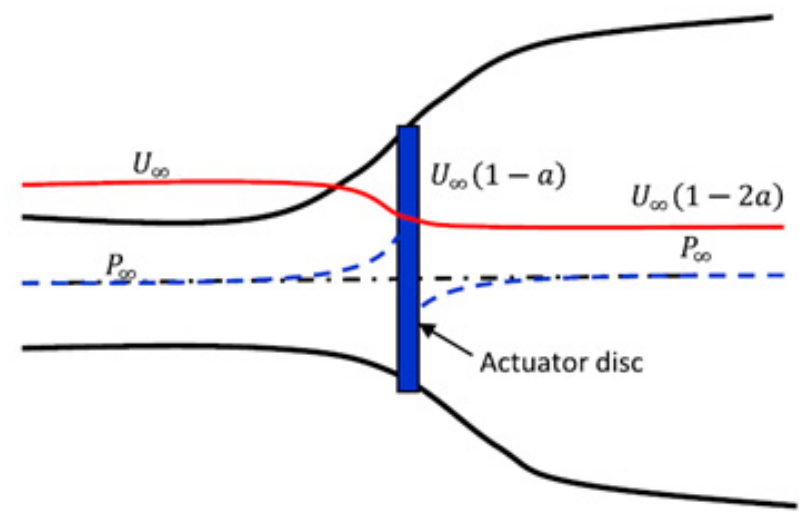

Fig. 1. Actuator disk model of a wind turbine in a stream tube.

lower uniform speed of $U_{\infty}(1-a)$ compared to the uniform wind speed $U_{\infty}$ which enters the rotor area. As can be seen in Figure 1 above, the reduction of wind speed in the direction of the axis is yielded by the axial induction factor, $a$. An annular element at radius $r$ with thickness of $\mathrm{dr}$ in a rotor area of $\mathrm{d} A=2 \pi r \mathrm{~d} r$, receives the differential thrust force, $\mathrm{d} T$; this happens as a result of a change in the step pressure in the actuator disk at the rotor area. The one-dimensional momentum theory can help calculate the thrust force in the following way [12]:

$$
\mathrm{d} T=4 a(1-a) \rho U_{\infty}^{2} \pi r \mathrm{~d} r
$$

In the above formula, $\rho$ indicates the average density of air at the height of the hub in the wind turbine. The ideal wind retardation in a wind turbine is two third of the value of the free stream; thus $a=1 / 3$, and this is in agreement with the maximum power coefficient of $C_{P \max }=16 / 27$, i.e. 0.593 . The wind turbine power is generated by a torsion torque given to the wind turbine rotor by the wind. When this torque is employed, in order for the moment of momentum to be conserved, a wake rotation downstream is used in the wind turbine. Figure 2 demonstrates an annular control volume of the actuator disk, through which a particle influenced by the wake rotation is passing [12].

An angular induction factor, $a$, can help define the induced wake rotation by $a^{\prime}=\omega / 2 \Omega$ where the wake rotation is indicated by $u$, and the angular velocity of the wind turbine rotor is shown by $\Omega$. The differential torque, $\mathrm{d} Q$, which is acted on the rotor annular element, $\mathrm{d} A=2 \pi r \mathrm{~d} r$, at radius $r$ is defined as follows based on the relations associated with the moment of momentum. The effects of the blade shape cannot be extracted from the momentum theory and the related relations given above. These effects are included in the blade element theory [12].

$$
\mathrm{d} Q=4 a^{\prime}(1-a) \rho U_{\infty} \Omega \pi r^{3} \mathrm{~d} r
$$

Figure 3 shows the airfoil section of a wind turbine with a horizontal axis. The following formula gives the relative wind speed, $U_{r e l}$, for this airfoil section [12].

$$
U_{\text {rel }}^{2}=U_{\infty}^{2}(1-a)^{2}+r^{2} \Omega^{2}\left(1+a^{\prime}\right)^{2}
$$




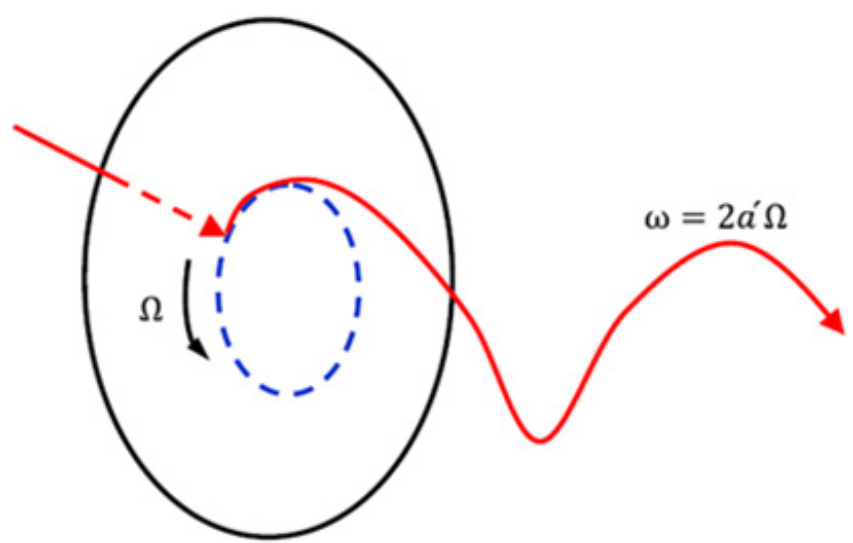

Fig. 2. A particle, affected by wake rotation, passing through the actuator disk.

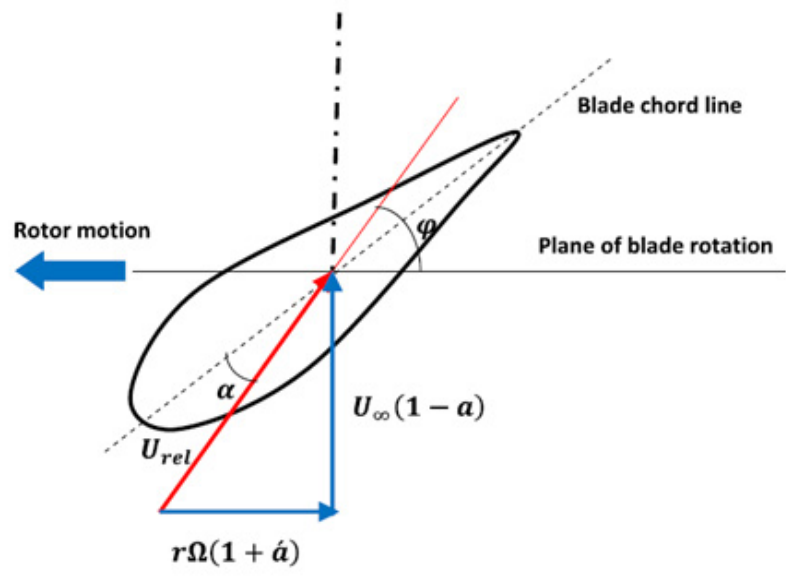

Fig. 3. The relative wind speed and wind angles over an airfoil section of blade.

This shows the vector sum of the reduced wind speed in the axis, $U_{\infty}(1-a)$, and the relative air speed considering the rotor motion with its blade section velocity and the induced angular velocity related to it, i.e. $\Omega r\left(1+a^{\prime}\right)$. Accordingly, we can calculate the relative angle of wind, $\varphi$, in relation to the blade rotation plane as follows [12]:

$$
\tan \varphi=\frac{U_{\infty}(1-a)}{\Omega r\left(1+a^{\prime}\right)}=\frac{(1-a)}{\lambda_{r}\left(1+a^{\prime}\right)}
$$

where $\lambda_{r}=\Omega r / U_{\infty}$ indicates the ratio of the radial (or local) speed which is calculated by considering the wind turbine rotor hub center to the radial distance of $r$, and $\Omega r$ shows the speed of the blade at the rotor radius of $r$. A design which includes wake rotation is much more difficult since the designer needs to consider the wake region and the rotational kinetic energy generation in it. This causes the rotor to capture less power compared to the theoretical limiting case of a design without a wake rotation [12].

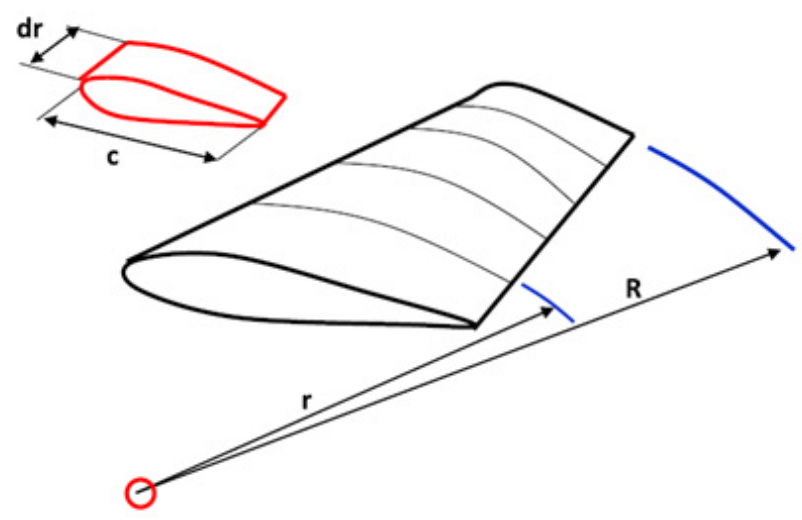

Fig. 4. The rotor blade and its elements in radial direction.

\subsection{The blade element method}

One drawback of the actuator disk theory is that it ignores drag force, and this is against the reality. As an attempt to compensate for this pitfall, the blade element theory tries to make use of the effects that the drag force has on two-dimensional airfoil sections for every one of the blades. This is demonstrated in Figure 4. Thus, $C_{l}$, as the local two-dimensional lift, $C_{\mathrm{d}}$, as drag, coefficients for the blade element, the thickness of which is shown as $\mathrm{d} r$, and $c$, as the length of the chord can be defined in the following relation [12].

$$
\begin{aligned}
C_{\mathrm{l}} & =\frac{\mathrm{d} F_{\mathrm{l}}}{\frac{1}{2} \rho U_{\mathrm{rel}}^{2} c \mathrm{~d} r} \\
C_{\mathrm{d}} & =\frac{\mathrm{d} F_{\mathrm{d}}}{\frac{1}{2} \rho U_{\mathrm{rel}}^{2} c \mathrm{~d} r}
\end{aligned}
$$

By the same token, $\mathrm{d} F_{N}$, indicating the local thrust force, and $\mathrm{d} Q$, indicating the local torque, which are acted on the local airfoil section are defined as below:

$$
\begin{aligned}
\mathrm{d} F_{N} & =B \frac{1}{2} \rho U_{\text {rel }}^{2}\left(C_{\mathrm{l}} \cos \varphi+C_{\mathrm{d}} \sin \varphi\right) c \mathrm{~d} r \\
\mathrm{~d} Q & =B \frac{1}{2} \rho U_{\text {rel }}^{2}\left(C_{\mathrm{l}} \sin \varphi-C_{\mathrm{d}} \cos \varphi\right) c \mathrm{~d} r
\end{aligned}
$$

where, the number of blades in the rotor area is shown by $B$, and the relative wind speed, which was defined earlier in (3), is shown by $U_{\text {rel }}[12]$.

\subsection{Tip losses}

Considering the area around the blade tip, before the air is sucked by the upper side of the blade, it usually enters the side with lower pressure, which causes a reduction in the amount of lift and power produced. Prandtl provided a model showing the effects of such a reduction. The fluctuation of the correction factor of tip loss, shown as $F$, is in the range of the value of zero, which happens around the blade tip, and unity values, which are true about almost all parts of the blade $(0<F<1)[13]$ :

$$
F=\frac{2}{\pi} \cos ^{-1}\left[\exp \left\{-\frac{B\left(\lambda-\lambda_{r}\right)}{2 \lambda_{r} \sin \varphi}\right\}\right]
$$


Table 1. Design parameters of the initial 1.5 MW turbine.

\begin{tabular}{ccc}
\hline Parameters & Value & Unit \\
\hline Generator rated power output, $P_{\mathrm{r}}$ & 1.5 & $\mathrm{MW}$ \\
Wind speed rated, $V_{\text {rated }}$ & 10.7 & $\mathrm{~m} . \mathrm{s}^{-1}$ \\
Number of blades, $B$ & 3 & \\
Tip speed ratio, $\lambda_{0}$ & 7 & \\
Rotor diameter & 70 & $\mathrm{~m}$ \\
Rotor speed & 20.5 & $\mathrm{rpm}$ \\
Wind speed (cut-in), $V_{\text {cut-in }}$ & 3 & $\mathrm{~m} . \mathrm{s}^{-1}$ \\
Wind speed (cut-Out), $V_{\text {cut-out }}$ & 25 & $\mathrm{~m} . \mathrm{s}^{-1}$ \\
\hline
\end{tabular}

Subsequently, with regard to relations (1) and (2) which helped calculate the aerodynamic forces based on the momentum theory, these aerodynamic forces can be remodeled as below: [13]

$$
\begin{aligned}
& \mathrm{d} T=4 F a(1-a) \rho U_{\infty}^{2} \pi r \mathrm{~d} r \\
& \mathrm{~d} Q=4 F a^{\prime}(1-a) \rho U_{\infty} \Omega \pi r^{3} \mathrm{~d} r
\end{aligned}
$$

Tip losses happen when the values of the above-mentioned forces come close to zero around the blade tip. It is the momentum theory which explains this phenomenon [13].

\section{Annual energy production (AEP)}

One of the important factors in evaluating the amount of energy produced by wind turbines is their annual energy production in different areas. This parameter can be calculated using the following equation:

$$
E=8760 \times \frac{1}{2} \eta \rho A \int_{\text {cut-in }}^{\text {cut-out }} V^{3} C_{\mathrm{p}}(V) f_{\text {Rayleigh }}(V) \mathrm{d} \nu
$$

where $\eta$ is the transmission efficiency (in percentage) of both mechanical and electronic systems of the wind turbine; $E$ is the amount of annual energy production in this equation; $\rho$ is air density, and $A$ is wind turbine rotor area (swept area of the wind turbine); $C_{\mathrm{p}}(V)$ is the power coefficient of the wind turbine, obtaining whose optimum value through the optimal design of blades shape is the aim of this study. And $f_{\text {Rayleigh }}(V)$ evaluates the wind speed distribution for a particular area [14].

\section{Characteristics of the initial wind turbine used in this article}

In this paper, a 1.5 MW wind turbine made by national renewable energy laboratory (NREL) as a reference model was used to validate the results of the optimization, with the specifications given in Table $1[14,15]$.

\section{Wind turbine blade design parameters}

\subsection{Design wind speed}

The design wind speed in this article was considered based on nominal wind speed. As shown in Table 1, the nominal wind speed of 10.7 is defined for this turbine.

\subsection{Designing of tip speed ratio and rotor speed in the studied wind turbine}

As we know, most wind turbines have three blades, and their tip speed ratio range is between 6 and 8 . In this paper, according to the amount of $V_{\text {rated }}$ used in the current study, the designed tip speed ratio was considered $\left(\lambda_{0}=7\right)$. With regard to the relationship of the tip speed ratio investigated in Section 2.1, the amount of the tip speed ratio was equal to $75 \mathrm{~m} . \mathrm{s}^{-1}$. However, the rotor speed of MW class wind turbine in this study was considered $20.5 \mathrm{rpm}$.

As noted in Table 1, the speed values of cut-in and cutout are 3 and $25 \mathrm{~m} . \mathrm{s}^{-1}$, respectively, and with respect to the related equations, the range of tip speed ratio is from 3.005 to 25.045 . In this study, the blade tip speed ratio was considered to be in the range of the cut-out speed to the rated speed.

\subsection{The type of the selected airfoil and the effect of Reynolds number}

Considering the fact that the analysis of large wind turbines is investigated in this study, NREL introduces various types of airfoils for different parts of the blade in large wind turbines with regard to structural and aerodynamic requirements of blades. Every one kind of these airfoils is used for a specific purpose. In this paper, according to valid results presented in NREL, airfoil S818 was used for the root of the blade, airfoil S825 was used for the middle of the blade, and airfoil S826 was used for the tip of the blade. One of the most important parameters that affect the performance of the selected airfoil is Reynolds number, which is presented as follows:

$$
R e=\frac{\rho v c}{\mu}
$$

where $\mu$ is the viscosity of air; $C$ is the airfoil chord length; $V$ is the wind speed acting on the airfoil; and $\rho$ reports the air density. According to the range of cut-in and cutout speeds in this paper which is from 3 to $25 \mathrm{~m} . \mathrm{s}^{-1}$, the studied range of Reynolds can be calculated and analyzed. If the value of $C$ for the middle of the blade $(r=17.5 \mathrm{~m})$ is considered $2 \mathrm{~m}$ approximately, Reynolds values can be calculated considering the related equations on the speed values acting on the airfoil section.

$$
\begin{aligned}
V_{\mathrm{tan}} & =\frac{\text { blade tip speed }}{2} \\
& =r_{\text {mid-section } \omega} \\
U_{\text {rel }} & =\sqrt{V_{\text {tan }}^{2}+v^{2}}
\end{aligned}
$$

The calculated Reynolds values for the desired speed range are obtained as from $5.1 \times 10^{6}$ to $6.27 \times 10^{6}$. A complete list of the Calculated Reynolds values is given in Table 2.

As can be seen, Reynolds changes in the selected range are negligible. As a result, to analyze the design in this 
Table 2. Estimated Reynolds numbers at different operation wind speed.

\begin{tabular}{cccc}
\hline$V\left(\mathrm{~m} . \mathrm{s}^{-1}\right)$ & $V_{\tan }\left(\mathrm{m} . \mathrm{s}^{-1}\right)$ & $U_{\text {rel }}\left(\mathrm{m} . \mathrm{s}^{-1}\right)$ & $R e$ \\
\hline 3 & 37.55 & 37.67 & $5.1 \times 10^{6}$ \\
7 & 37.55 & 38.20 & $5.3 \times 10^{6}$ \\
11 & 37.55 & 39.13 & $5.4 \times 10^{6}$ \\
19 & 37.55 & 42.08 & $5.8 \times 10^{6}$ \\
25 & 37.55 & 45.11 & $6.2 \times 10^{6}$ \\
\hline
\end{tabular}

paper the constant value of Reynolds was considered $6 \times$ $10^{6}$, and $C_{\mathrm{L}}$ and $C_{\mathrm{D}}$ values for the selected airfoil sections in this article were studied and analyzed in these values of Reynolds.

\section{Mathematical modeling of the rotor performance}

In every wind turbine, all blade elements cooperate together and provide the rotor with the required power; so, in order to be able to analyze the performance of the rotor, first, the performance of every individual blade element should be analyzed. This calculation is done by following an iterative procedure summarized below:

(1) the axial induction factors a, and the angular induction factor $a^{\prime}$ are given approximate values [16]:

$$
\begin{aligned}
& \varphi_{i, 1}=\left(\frac{2}{3}\right) \tan ^{-1}\left(\frac{1}{\lambda_{r, i}}\right) \\
& \propto_{i, 1}=\varphi_{i, 1}-\theta_{i, 1}
\end{aligned}
$$

According to the explanations in Section 5.3 of the paper selected airfoils along the length of the turbine blade. Information about the $C_{\mathrm{L}}-\alpha$ and $C_{D}-\alpha$ charts for the employed airfoils was extracted from XFoil Software according to the calculated Reynolds. Therefore, in this article, considering the calculation of $\alpha$ in the previous section, the values of $C_{\mathrm{L}}$ and $C_{\mathrm{D}}$ for different sections of the blades were extracted using the related diagrams of these airfoils. And these results were used in the later stages of the designing process [16].

$$
\begin{aligned}
a_{i, 1} & =1 /\left[1+\frac{4 \sin ^{2}\left(\varphi_{i, 1}\right)}{\sigma_{i}{ }^{\prime} C_{l, i} \cos \varphi_{i, 1}}\right] \\
a_{i, 1}{ }^{\prime} & =\frac{1-3 a_{i, 1}}{\left(4 a_{i, 1}-1\right)}
\end{aligned}
$$

where the $i$ th section of the blade is indicated by $i$, the speed ratio of the $i$ th blade section is indicated by $\lambda_{r, i}$, the distance between the $i$ th blade section and the center of the rotor is indicated by $r_{i}$, the relative angle of the wind at the $i$ th blade section is shown by $\varphi_{i}$. The axial induction factor of the $i$ th blade section is indicated by $a_{i, 1}$, the angular induction factor of the $i$ th blade section is indicated $a_{i, 1}{ }^{\prime}$, the lift coefficient related to the $i$ th blade section is shown by $c_{l, i}$, the attack angle of the $i$ th blade section is indicated by $\propto_{i, 1}$, and the twist angle of the $i$ th blade section is indicated by $\theta_{i, 1}[16]$.

The local solidity indicated by $\sigma_{i}^{\prime}$ can be calculated by:

$$
\sigma_{i}{ }^{\prime}=\frac{B c_{i}}{2 \pi r_{i}}
$$

(2) Then the first step is repeated for the $j$ th blade section, $j=1$; and both the relative wind angle and Prandtl tip loss factor are determined:

$$
\begin{aligned}
\tan \varphi_{i, j} & =\frac{1-a_{i, j}}{\left(1+a_{i, j}{ }^{\prime}\right) \lambda_{r, i}} \\
F_{i, j} & =\left(\frac{2}{\pi}\right) \cos ^{-1}\left[\exp \left(-\left(\frac{\left(\frac{B}{2}\right)}{\left(\frac{r_{i}}{R}\right) \sin \varphi_{i, j}}\right)\right)\right]
\end{aligned}
$$

(3) Next, the attack angle of the $i$ th blade element is specified:

But in this article, when twist $(\theta)$ is calculated, Equation (20) can be used to determine the attack angle $(\alpha)$.

$$
\alpha_{i, j}=\varphi_{i, j}-\theta_{i, j}
$$

(4) After that, with regard to the drag effects, the real values of the axial induction factor a and the angular induction factor $a^{\prime}$ are determined to be used in the next iteration:

$$
\begin{aligned}
a_{i, j+1} & =\frac{1}{\left[1+\frac{4 F_{i, j} \sin ^{2}\left(\varphi_{i, j}\right)}{\sigma_{i}{ }^{\prime}\left(C_{\mathrm{l}, i, j} \cos \varphi_{i, j}+C_{\mathrm{d}, i, j} \sin \varphi_{i, j}\right)} \frac{1}{H}\right]} \\
a_{i, j+1}{ }^{\prime} & =\frac{1}{\frac{4 F_{i, j} \sin \varphi_{i, j} \cos \varphi_{i, j}}{\sigma_{i}{ }^{\prime}\left(C_{\mathrm{l}, i, j} \sin \varphi_{i, j}-C_{\mathrm{d}, i, j} \cos \varphi_{i, j}\right.}-1}
\end{aligned}
$$

We can use the $H$ parameter in case, $H$ parameter has been defined when a is large to prevent divergence of the final response. In situations where the values of the axial induction factor a goes beyond 0.5 , we replace the equation for thrust coefficient [16]:

$$
C_{\mathrm{T}}=4 a(1-a)
$$

with the following equation:

$$
C_{T}=0.6+0.61 a+0.79 a^{2}
$$

In GH-bladed the transition for the axial induction factor is taken as being greater than 0.3539 instead of 0.5 so as to make the transition smoother. Thus, the following expression can define the parameter $H$ [17]:

$$
\begin{aligned}
& \text { for } a_{i, j+1} \leq 0.3539, H=1.0 \\
& \text { for } a_{i, j+1}>0.3539, H=\frac{4 a(1-a)}{\left(0.6+0.61 a+0.79 a^{2}\right)}
\end{aligned}
$$

At this stage, we must make sure that the $j+1$ th and the $j$ th induction factors are not too much deviated, only then 
should the following elements be verified: the local relative wind angle $\varphi_{i}$, tip loss factor $F_{i}$, and attack angle $\alpha_{i}$, based on which the local lift and drag coefficients $C_{l, i}$ and $C_{d, i}$ for the $i$ th blade element are calculated; otherwise, we need to return to the second step. When these important parameters of performance are determined for all blade elements, the blade element torque can be determined with regard to Equation (8):

$$
\mathrm{d} Q_{i}=F_{i} B \frac{1}{2} \rho U_{\mathrm{rel}, i}^{2}\left(C_{l, i} \sin \varphi_{i}-C_{\mathrm{d}, i} \cos \varphi_{i}\right) c_{i} r_{i} \mathrm{~d} r
$$

Reference [18] helps determine the total torque and power of the rotor:

$$
\begin{aligned}
& Q=\sum_{i=1}^{n} \mathrm{~d} Q_{i} \\
& P=Q \Omega
\end{aligned}
$$

Now, it is possible to calculate the rotor power coefficient by $[16]$ :

$$
C_{P}=\frac{P}{\frac{1}{2} \rho \pi R^{2} V^{3}}
$$

\section{Artificial neural networks (ANNs)}

Neural networks are, in many ways, similar to a human's brain. These networks, which are in fact an artificial form of our brain, are made up of neurons, each of which has the role of carrying out a simple computation. But their role is surely not as complicated as that of biological neurons. The structure of ANNs is in the form of some layers, and each of these layers is connected to some other hidden layers; these connections make computation possible. Every one of the neurons in the hidden layer is connected to all neurons in the output layer; as their name suggests, output layers are responsible for providing the output of the processing. ANNs are programmed and trained by some algorithms which are based on the learning laws. These particular algorithms are supposed to simulate the mechanisms of learning that a biological system goes through. Pattern recognition, system identification, trend prediction and process control are among the complicated performances that can be learned by a neural network [19].

\subsection{RBF neural network}

There are different types of artificial neural networks. One type of ANN is the radial basis function (RBF) neural network which uses radial basis functions as activation functions. This ANN is a linear combination of radial basis functions. The RBF neural networks typically have three layers: an input layer, a hidden layer with nonlinear $\mathrm{RBF}$ activation functions and a linear output layer [18]. Figure 5 shows the general structure of an RBF neural network.

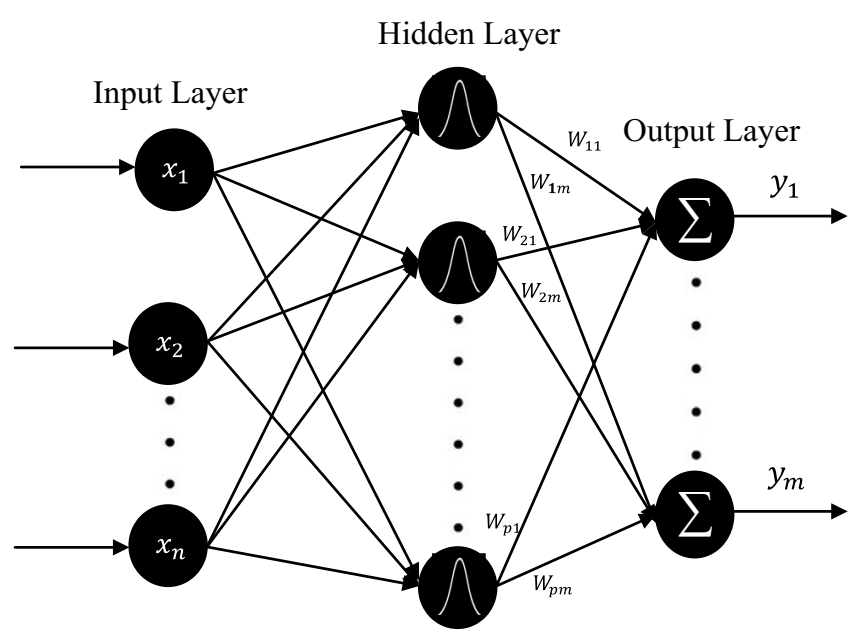

Fig. 5. The general structure of RBF neural network.

\section{Genetic algorithm}

The Genetic Algorithm follows an iteration-based approach. Holland grounded this method on the following principles: natural selection, genetic and evolution [19]. Every possible solution is encoded in the form of strings which are named as chromosomes. These chromosomes comprise a network of sub-strings, each of which stands for one feature of the possible solution. GA makes use of various techniques of encoding like binary, real-valued and complex-valued. In this algorithm, single bit-strings can carry the full description of most individuals; as a result, a genotype is identified with only one single chromosome. Choosing the best encoding procedure among all available ones is not an easy task. This selection is dependent upon the application. For instance, one study [20] proved that in problems of designing the shape of the fluid flow, higher rate of convergence can be provided by continuous GA. Among the three operators of GA, which are crossover, mutation and selection, the first two are applied for the population of solutions so that they can reach a higher level of overall fitness through having interactions with each other. Individuals are selected for reproduction with a probability depending on their fitness. Here, GA allocates the mating probability of each individual proportionally to its fitness (proportional selection) and chooses the parents set through the roulette wheel selection procedure [21]. Fitness ranking and tournament selection can also be mentioned as common schemes of selection [22]. Is suggested to those readers who like to have more information about the different schemes of selection. Among the search operators, crossover is the most important one. It makes a random mixture of the parental genome sections, and thus offsprings are created. Implementing GA leads to a large increase in the number of exchanged sections. Some of the crossover procedures are more frequently applied than others; included are one-point crossover, twopoint crossover, uniform and arithmetic crossover [23]. In order to keep the operator frequency under control, the probability of crossover is checked. Setting this factor at 0.67, this study exploited arithmetic crossover. Genetic 


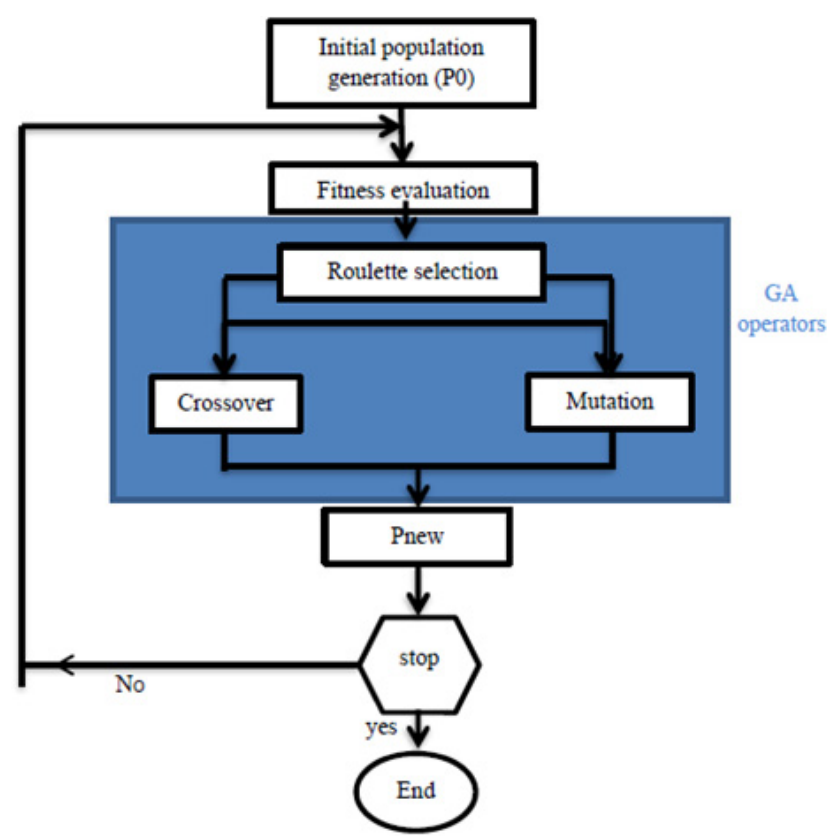

Fig. 6. Flow diagram of the genetic algorithm as employed in this paper.

mutation was then employed based on a random selection of some offsprings. The information of one bit-string, which is randomly chosen by the mutation operator, is flipped in a narrow range. Applying iterations, mutation plays the role of keeping the heterogeneity in the population. The GA utilizes generational replacement, a fact that is common among all EAs. The procedure begins by making an initial population including some possible solutions. Then, in an iterative process, every individual is checked for fitness, and the appropriate ones are chosen for crossover and mutation, which are supposed to yield the new population. The iterations continue to apply for a good deal of generations until the criterion for stop is fulfilled. This criterion is fulfilled when the whole algorithm experiences a particular number of cost evaluations. The above procedure of GA followed in this study, is demonstrated in Figure 6.

\section{The bees algorithm}

The way bees search for available nectar near their hive spired the bees algorithm (BA) [24], in which a number of scout bees enter the target area and every location is explored by one bee. Then each location is assessed for fitness (in the algorithm, possible solutions are evaluated), and the ones enjoying higher fitness are selected. These locations are filtered again and the best ones are labeled as elite locations. Having more bees explore the elite locations than the other selected locations, a better solution is looked for by the algorithm. When the searching phase is completed, one bee which enjoys the highest fitness value is allowed to form a new population of bees. Finally, those bees coming back from locations which were not selected (due to lower fitness) are assigned to look for new possible solutions in the area. Only when the criterion for stop is satisfied, are these iterations stopped. Accordingly, one can summarize the following important factors in the algorithm: number of searching bees $(n)$, number of locations with higher fitness $(m)$, number of elite locations selected from $m(e)$, number of bees exploring elite locations (nep), number of bees exploring other $(m-e)$ selected locations $(n s p)$, and finally, the criterion for stop. For the purposes of the current study, some small changes were made in the form of the BA explained earlier, in that the way the selected locations and the elite locations were determined differs. Here, considering the degree of fitness, a probability factor was assigned to each location; thus locations with higher fitness were more likely to be among selected locations. This was done using the following probability function:

$$
p_{i}=\left\{\begin{array}{cc}
0.4 & f_{i}<0.9 \\
0.8 & 0.9<f_{i}<0.95 \\
0.95 & 0.95<f_{i}<1.15 \\
1 & f_{i}>1.15
\end{array}\right.
$$

Here, the probability of location $i$ to be among the selected locations is indicated by $p_{i}$, and the fitness of location $i$ is indicated by $f_{i}$. There is also a relation between the number of scout bees in the selected locations and the fitness of those locations. A number shown as $n B e e 0$ indicates this proportional relation as below:

$$
n s p_{i}=n B e e 0 \times f_{i}
$$

Being a constant, nBee0 equals 3 , unless stated otherwise. The BA as employed in the present research study is demonstrated in a flow diagram in Figure 7.

\section{Hybrid algorithm}

\subsection{Idea of hybrid algorithms}

Hybridization of algorithms originates from various fields of computational intelligence. This topic has attracted the attention of many researchers in recent years. Research has shown that individual techniques (such as neurocomputing, fuzzy systems, rough sets, evolutionary algorithms, etc.) which are based on computational intelligence, cannot give as well a performance as hybrid algorithms do. Such combinations have proved to be of great use to researchers dealing with some of the very important problems. In order to find a satisfactory solution to a specific problem, a number of different techniques are combined to be employed in a hybrid intelligence system.

\subsection{Hybrid of BA and GA}

As stated earlier, the advantage of GA is better exploration of vast areas, while the drawback is in dealing with 


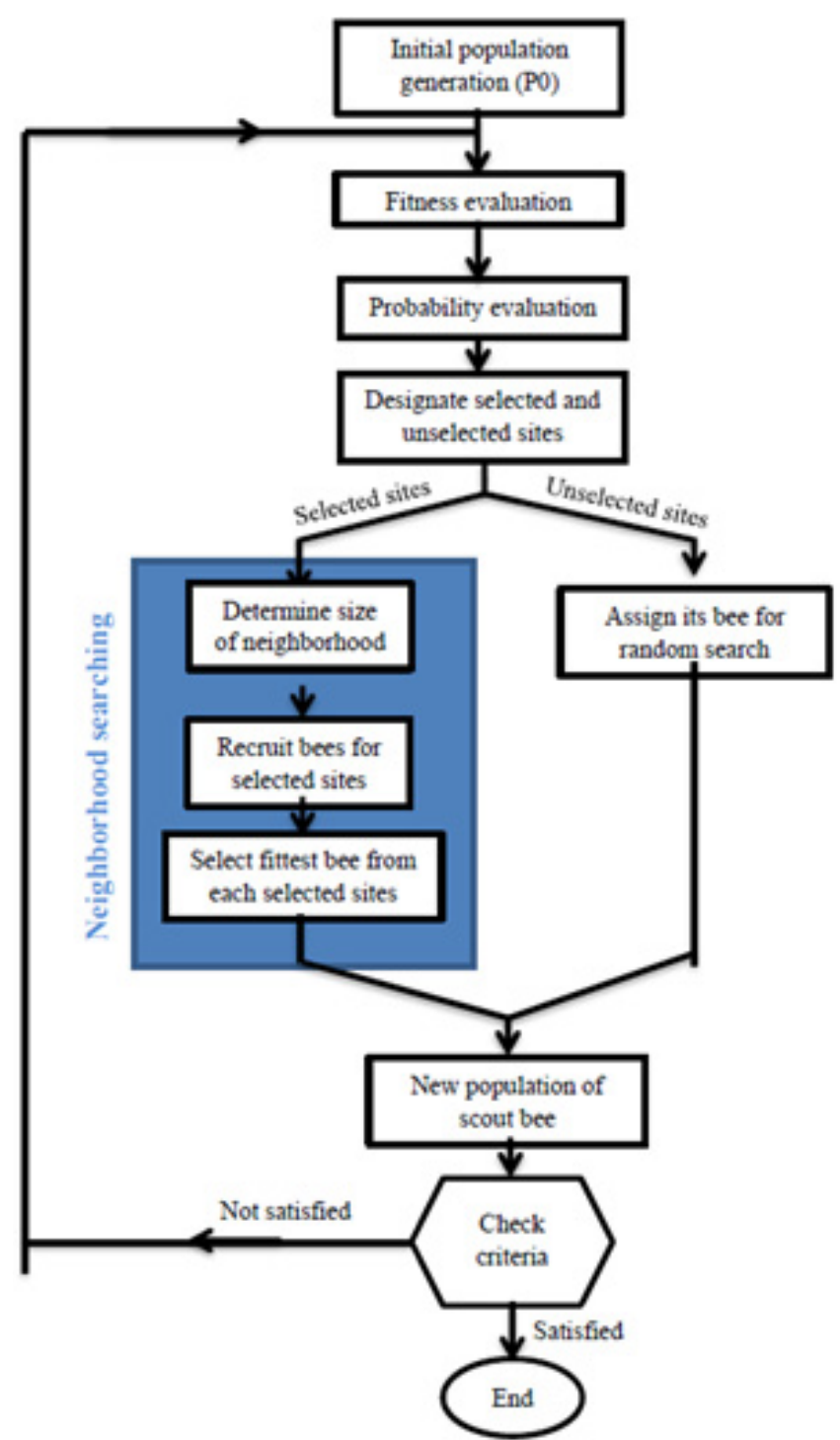

Fig. 7. Flow diagram of the Bees algorithm as employed in this paper.

the local optima. On the contrary, BA is more capable of searching for global optima, but it suffers from being slow in searching large spaces [25-27]. The current study employed a new algorithm which is in fact a combination of GA's crossover and BA's operators of searching the neighborhood. Thus, this algorithm enjoys the merits of both GA and BA. In this algorithm, iterations should not necessarily apply the same number of operators. The possible number of applied operators of GA and BA is identified in here based on the criterion of diversity. Different evolutionary algorithms apply this criterion in different manners [28]. In the case of this study, diversity refers to the magnitude of exploring space, which is determined through the following formula:

$$
d=\frac{\sum_{i=1}^{n P o p}\left|f_{i}-\bar{f}\right|}{\bar{f}}
$$

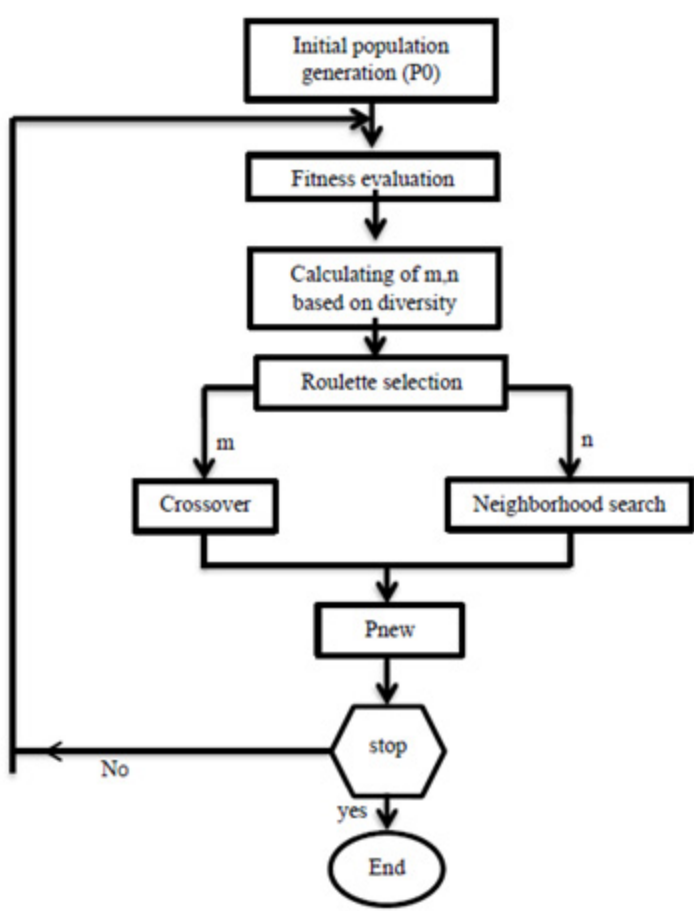

Fig. 8. Flowchart of the hybrid algorithm (GBBA) used in this study.

where $f$ shows the fitness of the individual $\mathrm{I}$, and $\bar{f}$ indicates the mean fitness of the population (i.e. all individuals). The selected portion of population for crossover operator $(m)$ is a function of diversity. This is determined as follows:

$$
m=\min \{100 \%,(d \times A)\}
$$

Variable $A$ is a constant, but it can change in other problems. Here, A equals 80 unless stated otherwise. Neighborhood searching is to be done by the rest of the population. In this suggested hybrid algorithm, first, the initial population is evaluated for generation and fitness, and then we calculate diversity. After that, applying roulette selection mechanism, $m$ numbers of individuals are chosen for crossover and $n$ numbers of them are chosen for neighborhood searching. All individuals, including those selected for crossover, have the chance of being selected for neighborhood searching. In order to form the new population, the best individuals are chosen from among the combination of the old population and the results obtained from crossover and neighborhood searching operators. This procedure is iterated and the algorithm returns to fitness evaluator section, until the criteria for stop are met. The following flow diagram in Figure 8 demonstrates the procedure of the hybrid algorithm proposed in this study:

\subsection{Hybrid of BAT and HS}

This paper made use of the results obtained from the HSBBA algorithm, which were discussed in reference [29], 
for the purpose of optimizing the power generation of wind turbines for the first time.

\section{Objective function}

One of the important issues in the analysis of the optimization is the objective function. In this paper, in order to maximize the output power (as $C_{\mathrm{P}}$ ) and minimize solidity considering the design process defined in this study, the objective function is defined as follows:

$$
\text { objective function }=w C_{\mathrm{p}}+(1-w) \sigma^{-1}
$$

Therefore, the optimization algorithms used in this study offer different forms of wind turbines blades; and in the function evolution section, each algorithm is described by applying the BEM theory; then, in Section 6, the efficiency of each designed blade is evaluated and the results are stored and displayed in the objective function.

\section{Determination of the appropriate weighting factor}

In the multi-dimensional optimization method, usually a single optimum design is rarely attained. Additionally as it is clear, the Pareto fronts represent the locus of optimum blades for the two- dimensional optimization method. The most important problem is to designate the suitable value of $w$ for the final design; on the other hand, it is important to determine which point along the Pareto front forms the final design which is optimum. It is important to consider that for multi-dimensional analysis, we usually choose the " $w$ " values bigger than 0.7 . This is due to the fact that for lower values of $w$, the importance of the output power which is a primary aim for designing the wind turbine blade drops in the objective function. In this paper, $w=0.9$ is considered.

\section{Design constraints}

One of the challenges faced by the designer in designing blades of large wind turbines is to achieve a reasonable distribution of chord and twist. According to the investigation into chord and twist distributions carried out in this paper, and the sensitivity of the analysis of their distributions, in order to achieve a reasonable distribution for these parameters, it is required to apply constraints in designing the blades. The main objective of this study is to optimize the aerodynamic shape of the blades; broader analyses of structural areas can be discussed in future studies. For this reason, here, by applying the initial design constraints, it is tried to achieve a reasonable distribution for twist and chord.
Table 3. Chord, twist and airfoil distributions along the original blade [14].

\begin{tabular}{cccc}
\hline$R, \mathrm{~m}$ & Chord, $\mathrm{m}$ & Twist, deg & Airfoil \\
\hline 7.875 & 2.72 & 10.5 & $\mathrm{~S} 818$ \\
9.625 & 2.64 & 9.1 & $\mathrm{~S} 818$ \\
11.375 & 2.52 & 7.6 & $\mathrm{~S} 818$ \\
14.875 & 2.27 & 6.1 & $\mathrm{~S} 818$ \\
16.625 & 2.14 & 3.4 & $\mathrm{~S} 825$ \\
18.375 & 2.02 & 2.6 & $\mathrm{~S} 825$ \\
20.125 & 1.9 & 2.1 & $\mathrm{~S} 825$ \\
21.875 & 1.77 & 1.7 & $\mathrm{~S} 825$ \\
23.625 & 1.65 & 1.2 & $\mathrm{~S} 825$ \\
25.375 & 1.53 & 0.8 & $\mathrm{~S} 825$ \\
28.875 & 1.3 & 0.5 & $\mathrm{~S} 825$ \\
30.625 & 1.18 & 0.3 & $\mathrm{~S} 826$ \\
32.375 & 1.07 & 0.2 & $\mathrm{~S} 826$ \\
34.125 & 0.96 & 0.1 & $\mathrm{~S} 826$ \\
\hline
\end{tabular}

(a) With the aim of efficiently using the materials used in designing large wind turbines blades, we act in such a way that the torque of each element around the root has no difference more than $10 \%$ to the rest of the blade elements.

(b) The maximum power generation, which is obtained based on the optimal $C_{\mathrm{p}}$ value, should not be more than $120 \%$ of the nominal power for the cut-out speed.

\section{Wind PACT 1.5 MW wind turbine for validation}

In this article, in order to evaluate the results obtained from the analysis of designing the blade of a large wind turbine, at first, results of designing a 1.5 MW wind turbine made by NREL are compared with the results of the analysis of the mathematical modeling used in this article (BEM theory). Characteristics of a $1.5 \mathrm{MW}$ wind turbine used in the reference model are presented in Tables 1 and $3[14,15]$ and $[30,31]$. The results of Figure 9 show that the analysis conducted on the mathematical modeling used in an article using the initial characteristics of the studied wind turbine are in good agreement with the results of designing the desired 1.5 MW wind turbine.

\section{Optimum Blade design}

\subsection{Methodology}

The main objective of this paper was to increase the power generation, while considering the reduction of solidity parameter for large wind turbines, using a new optimization method and investigating the aerodynamic parameters. As explained in the previous sections of the article, here, it is intended to investigate and compare different functions for the distribution of chord and twist as 
E. Assareh and M. Biglari: Mechanics \& Industry 17, 607 (2016)

Table 4. Equations for Chord and Twist distribution.

\begin{tabular}{ccc}
\hline Equation & Chord distribution & Twist distribution \\
\hline Quadratic & $C_{i}=a r_{i}^{2}+b r_{i}+c$ & $\theta_{i}=a r_{i}^{2}+b r_{i}+c$ \\
Cubic & $C_{i}=a r_{i}^{3}+b r_{i}^{2}+c r_{i}+d$ & $\theta_{i}=a r_{i}^{3}+b r_{i}^{2}+c r_{i}+d$ \\
Quartic & $C_{i}=a r_{i}^{4}+b r_{i}^{3}+c r_{i}^{2}+d r_{i}+e$ & $\theta i=a r_{i}^{4}+b r_{i}^{3}+c r_{i}^{2}+d r_{i}+e$ \\
Quintic & $C_{i}=a r_{i}^{5}+b r_{i}^{4}+c r_{i}^{3}+d r_{i}^{2}+e r_{i}+f$ & $\theta_{i}=a r_{i}^{5}+b r_{i}^{4}+c r_{i}^{3}+d r_{i}^{2}+e r_{i}+f$ \\
Exponential & $C_{i}=a \mathrm{e}^{b r_{i}}$ & $\theta_{i}=a \mathrm{e}^{b r_{i}}$ \\
Logarithmic & $C_{i}=a \ln \left(r_{i}\right)+b$ & $\theta_{i}=a \ln \left(r_{i}\right)+b$ \\
\hline
\end{tabular}

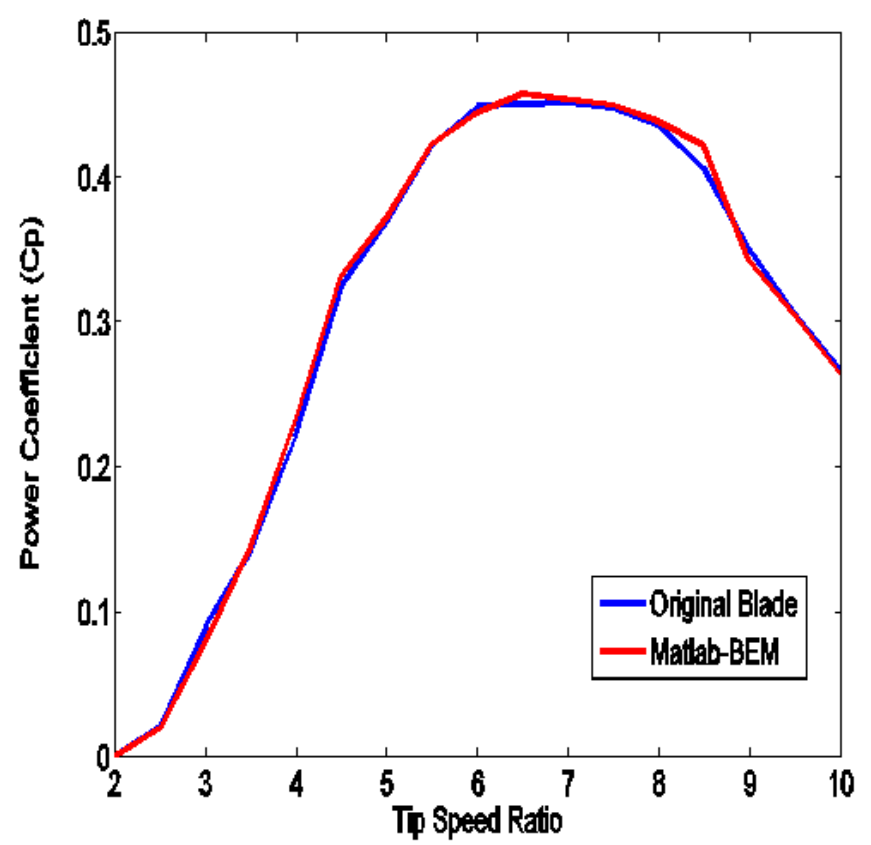

Fig. 9. Calculated power coefficient-tip speed ratio curve.

three presented scenarios, and compare the results of the intelligent algorithms used in the article. The three scenarios studied in $r_{i}$ to calculate the distribution of Chord and Twist are as follows:

Scenario 1: Chord and Twist distributions along the blade are considered linear and dependent on the introduced parameters:

$$
\begin{gathered}
C_{i, n}=C_{\mathrm{t}, 0}+\left(0.7 C_{\mathrm{r}, 0}-C_{\mathrm{t}, 0}\right) \frac{(n-1)}{N} \frac{r_{i}}{R} n=1,2, \ldots, N+1 \\
\theta_{i, n}=\theta_{\mathrm{t}, 0}+\left(0.7 \theta_{r, 0}-\theta_{t, 0}\right) \frac{(n-1)}{N} \frac{r_{i}}{R} n=1,2, \ldots, N+1
\end{gathered}
$$

In the above formula, the $n$th linearized chord line is shown by $n$, the chord at the $i$ th blade element of $n$ is shown by $C_{i, n}$, the twist angle at the $i$ th blade element of the $n_{\text {th }}$ linearized twist line is shown by $\theta_{i, n}$, the chords at the tip and the root of the initial blade are indicated by $C_{\mathrm{t}, 0}$ and $C_{\mathrm{r}, 0}$, the twist angles at the tip and the root of the initial blade are indicated by $\theta_{\mathrm{t}, 0}$ and $\theta_{r, 0}$, and finally, the number of divisions is indicated by $N$.

Scenario 2: The distribution of Twist and Chord is considered non-linear according to the following equations
Table 5. Specifications of trained RBF neural network.

\begin{tabular}{cc}
\hline Parameters & Values \\
\hline Input neurons & 2 \\
Hidden neurons & 6 \\
Output neurons & 3 \\
Learning rate & 0.25 \\
Basis width & 0.34 \\
Training time (s) & 0.62 \\
\hline
\end{tabular}

(Quadratic (polynomial of degree two), cubic (polynomial of degree three), quartic (polynomial of degree four), quintic (polynomial of degree five), exponential and logarithmic equations with the highest standard deviation $R^{2}$ ). Nonlinear equations for the distribution of chord and Twist versus $r_{i}$ changes used in this scenario have been shown as Table 4.

Functions coefficients values in this scenario are calculated using care fitting tool in MATLAB.

Scenario 3: The distribution of Twist and Chord is estimated based on artificial neural network. In this scenario, a neural network has been used as a tool to estimate the distribution of chord and Twist. Here, according to the type of data behavior of chord and Twist, artificial neural network of RBF has been used. The structure of used neural network has been shown in Table 5 .

Another main objective of this paper is to introduce a new intelligent optimization method for designing optimized blades of a large wind turbine. For this purpose, in this article by investigating different distributions of chord and twist and applying the related mathematical modeling (BEM theory), different values for the coefficient of power $\left(C_{\mathrm{P}}\right)$, which ultimately leads to power generation, are achieved.

Finally, with regard to the minimum amount of solidity and comparing the optimization algorithms used in this article, the obtained maximum power generation $\left(C_{\mathrm{p}}\right)$ was selected as the final optimal mode.

\subsection{Result and discussion}

In this section, the results of the analysis in this study are examined and discussed. Three scenarios were investigated for chord and twist distributions. Considering $N=19$ for the first scenario, 20 linear models were considered for the chord and twist. Scenario 2 included 6 nonlinear models whose coefficients were calculated by 
Table 6. Best model for the twist and chord distribution using the two hybrid algorithms.

\begin{tabular}{ccccc}
\hline \multirow{2}{*}{ Algorithms } & \multicolumn{2}{c}{ Chord distribution } & \multicolumn{2}{c}{ Twist distribution } \\
\cline { 2 - 5 } & Equation & Scenario & Equation & Scenario \\
\hline HSBBA & Cubic & 2 & ANN function & 3 \\
GBBA & Quantic & 2 & Quantic & 2 \\
\hline
\end{tabular}

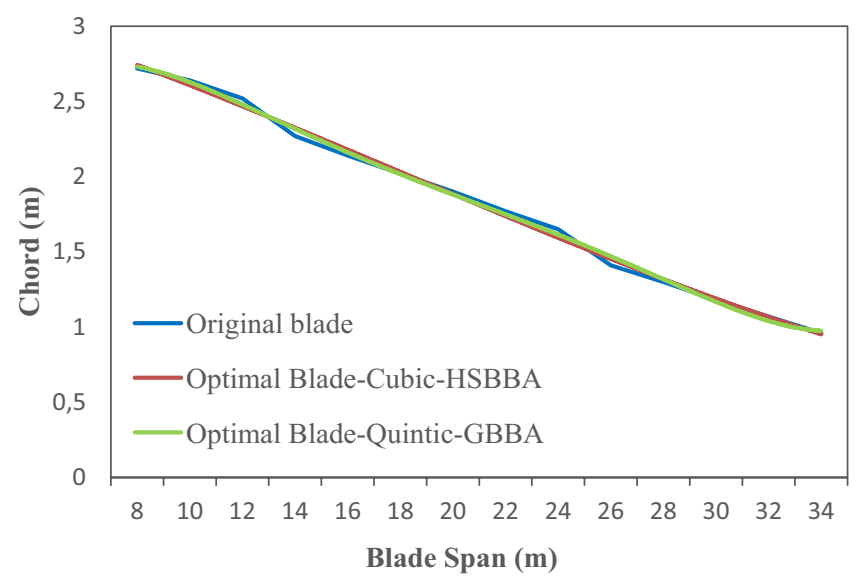

Fig. 10. Comparison of Chord distribution.

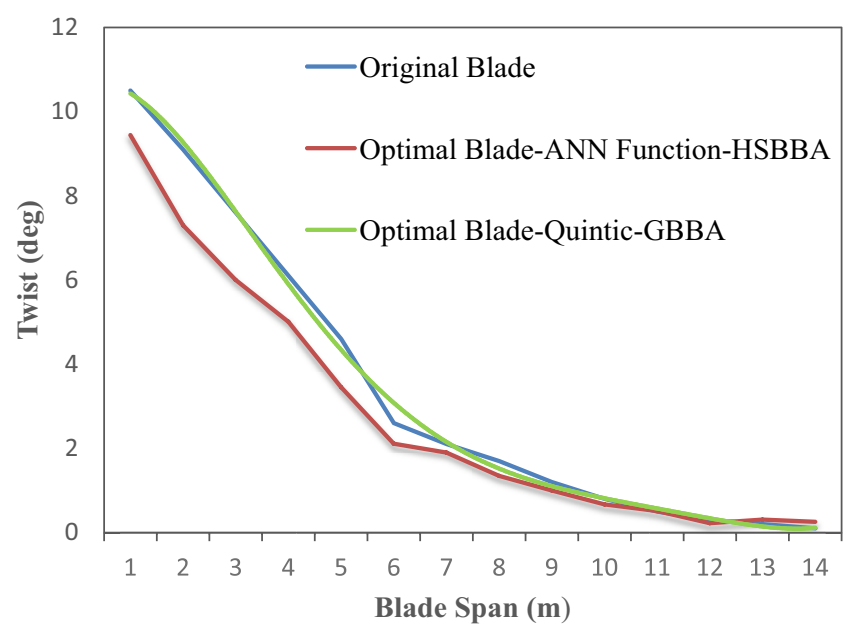

Fig. 11. Comparison of Twist distribution.

care fitting tool of MATLAB software. And scenario 3 presented distributions for chord and twist by means of artificial neural network. Consequently, to achieve a reasonable and precise distribution for twist and chord, the above scenarios were combined, and finally, 729 models were proposed for designing twist and chord, among which the best model was selected for the final design of the twist and chord distribution using the two hybrid algorithms as shown in Table 6. Also, the distributions of the chord and Twist have been compared with preliminary blade for HSBBA and GBBA algorithms in Figures 10 and 11 .

The best results of the design process of this paper for calculating the maximum coefficient of power and minimizing solidity using the two employed hybrid algorithms are compared in Table 7.
Table 7. Performance analysis results.

\begin{tabular}{cccc}
\hline \multirow{2}{*}{ Model } & Rotor solidity $(\sigma)$ & $C_{\mathrm{p}}$ & $C_{\mathrm{p}, \max }$ \\
\cline { 2 - 4 } & & & - \\
\hline HSBBA & 0.043 & 0.5012 & 0.5063 \\
GBBA & 0.040 & 0.5044 & 0.5097 \\
\hline
\end{tabular}

According to the tables, the following results are achieved:

(1) The results show that the method proposed in this paper (GBBA) provides better results.

(2) As can be seen in the results, Quantic distribution for chord length and Quintic distribution for twist angle using GBBA present greater coefficient of power than the other models, and are offered for chord and twist, respectively.

(3) The results show that the maximum coefficient of power for $2.58 \mathrm{~m}$ root chord length and $10.43 \mathrm{deg}$ root twist angle was obtained. These results can significantly help the designer in designing.

As a result, according to the above explanations, the most optimal model for the design of blades of large wind turbines is the presented model based on the results of this study in part 2 .

It is noteworthy that the maximum power output based on the turbine designed with an optimized blade at the cut-out speed of $25 \mathrm{~m} . \mathrm{s}^{-1}$ equals $2.2 \mathrm{MW}$, which is in the range of less than $120 \%$ limitation of output power $(120 \% \times 2.2=2.64 \mathrm{MW})$. In the present study, the maximum power generation for the optimized $\mathrm{Cp}$ was calculated as 2.46 MW, which is in the defined range. A comparison of the average annual energy production (AEP) for the original and the introduced optimized model at different average speeds of the wind is given in Table 8.

The results show that in the studied tip speed ratio range, AEP values for the provided design in this article are greatly increased.

\subsubsection{Evolution of the Ability to find global optimum points for getting higher power output value and convergence rate using evolutionary algorithms}

Figure 12 demonstrates the optimal blade model and the iterative design algorithms converged in it, as well as the variation in the power coefficient $(\mathrm{Cp})$ for the evolving generations. According to the numerical results, the accuracy of the solution provided by the GBBA is higher than that of the HSBBA by 0.67 percent. It is worth mentioning that the stop criteria were satisfied for all algorithms after about 30 iterations.

Moreover, the time that every algorithm needed to perform each generation update in the model of optimal blade is noted in Table 9. The PC which was used to carry out the computations of this study had an Intel (R) core i5 processor with $2.5 \mathrm{GHz}$ clock speed. As the table shows, comparing the proposed hybrid method with the HSBBA, there is no significant difference in the execution time per generation update. Although in terms 
E. Assareh and M. Biglari: Mechanics \& Industry 17, 607 (2016)

Table 8. AEP of the optimal blade and the preliminary blade.

\begin{tabular}{cccccc}
\hline Tip Speed & AEP (MWh/yr) & $\begin{array}{c}\text { AEP (MWh/yr)-Optimal } \\
\text { Blade by HSBBA }\end{array}$ & $\begin{array}{c}\text { AEP (MWh/yr)-Optimal } \\
\text { Blade by GBBA }\end{array}$ & $\begin{array}{c}\text { Increase } \\
\text { Rate-HSBBA }\end{array}$ & $\begin{array}{c}\text { Increase } \\
\text { Rate-GBBA }\end{array}$ \\
\hline 6 & 4829 & 4883 & 4902 & $1.12 \%$ & $1.51 \%$ \\
7 & 4818 & 4877 & 4892 & $1.22 \%$ & $1.54 \%$ \\
8 & 4786 & 4857 & 4868 & $1.48 \%$ & $1.71 \%$ \\
8.5 & 4765 & 4841 & 4850 & $1.59 \%$ & $1.78 \%$ \\
\hline
\end{tabular}

Table 9. Parameter setting and results obtained from different algorithms.

\begin{tabular}{cccccc}
\hline $\begin{array}{c}\text { Optimization } \\
\text { method }\end{array}$ & $\begin{array}{c}\text { Time }(\min ) \\
\text { per solution }\end{array}$ & $\begin{array}{c}\text { Number } \\
\text { of iterations }\end{array}$ & $\begin{array}{c}\text { Max } C \text { p-Original } \\
\text { blade }\end{array}$ & $\begin{array}{c}\text { Max } C \text { p-Optimal } \\
\text { blade }\end{array}$ & $\begin{array}{c}\text { Increase } \\
\text { rate }\end{array}$ \\
\hline HSBBA & 0.68 & 30 & 0.506 & 0.5063 & $0.06 \%$ \\
GBBA & 0.57 & 30 & 0.506 & 0.5097 & $0.73 \%$ \\
\hline
\end{tabular}

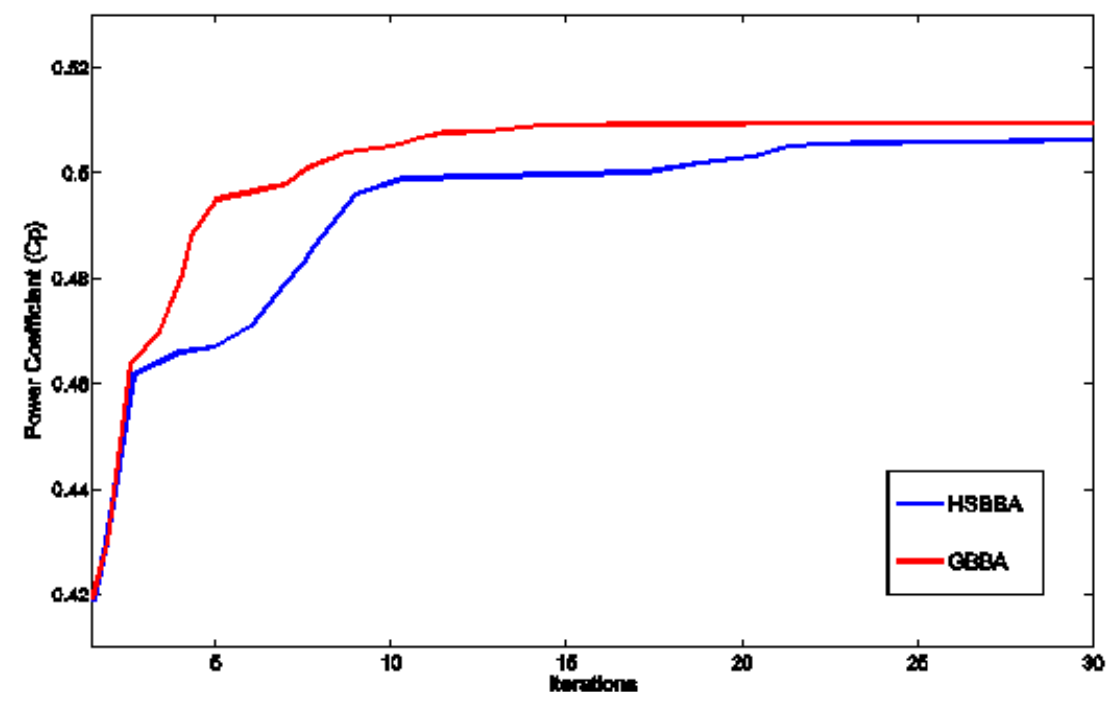

Fig. 12. Convergence history of different algorithms.

of cost-effectiveness, the GBBA algorithm is more costly, but the results show that making use of GBBA to design the optimal blade brings about a significant increase in the power coefficient $\left(C_{\mathrm{p}}\right)$ of the wind turbine. Table 9 shows the calculated $C_{\mathrm{p}}$ obtained from both the optimal blade and the original blade.

\section{Conclusion and future work}

In this paper, optimizing the design of wind turbines blade using intelligent algorithms methods and introducing a new optimization method was performed. In addition, attempts were made to achieve the main objective of this article by studying the different distributions for chord and twist. Finally, the results were validated by a valid reference model made at NREL.

Suggestions and opinions of authors are presented as follows:

1. The introduction of the selected distributions, in this article, for chord and Twist, which led to increasing the power generation of large wind turbines, can reduce the materials consumption in the manufacture of blades, and ultimately the cost of manufacturing the blades.

2. The new optimization method (GBBA), which was presented using the useful features of algorithms GA and $\mathrm{BA}$, can be used in all optimization processes related to wind turbines and other engineering problems as a useful technique.

3. The general method presented in this paper can be used to design all large wind turbines.

4. Applying the solidity parameter as one of the components of the objective function can be effective in improving the performance of large wind turbines at high wind speeds, and provides a good idea for the designer to design better blades.

\section{References}

[1] D. Saeidi, A. Sedaghat, P. Alamdari, A. Akbar Alemrajabi, Aerodynamic design and economical evaluation of site specific small vertical axis wind turbines, Appl. Energy 101 (2013) 765-775

[2] A. Sharifi, M.R.H. Nobari, Prediction of optimum section pitch angle distribution along wind turbine blades, Energy Convers. Manage. 67 (2013) 342-350 
[3] B. Kim, W. Kim, S. Lee, S. Bae, Y. Lee, Developement and verification of a performance based optimal design software for wind turbine blades, Renew. Energy 54 (2013) 166-172

[4] R.W. Vesel Jr., J.J. McNamara, Performance enhancement and load reduction of a $5 \mathrm{MW}$ wind turbine blade, Renew. Energy 66 (2014) 391-401

[5] R.K. Singh, M. Rafiuddin Ahmed, Blade design and performance testing of a small wind turbine rotor for low wind speed applications, Renew. Energy 50 (2013) 812819

[6] A. Pourrajabian, M. Mirzaei, R. Ebrahimi, D. Wood, Effect of air density on the performance of a small wind turbine blade: A case study in Iran, J. Wind Eng. Ind. Aerodyn. 126 (2014) 1-10

[7] S.M. Mortazavi, M.R. Soltani, H. Motieyan, A Pareto optimal multi-objective optimization for a horizontal axis wind turbine blade airfoil sections utilizing exergy analysis and neural networks, J. Wind Eng. Ind. Aerodyn. 136 (2015) 62-72

[8] A. Joodaki, A. Ashrafizadeh, Surface shape design in fluid flow problems via hybrid optimization algorithms, Aerospace Sci. Technol. 39 (2014) 639-651

[9] A. Vicini, D. Quagliarella, Airfoil and Wing Design Through Hybrid Optimization Strategies, 16th AIAA Applied Aerodynamic conference, New Mexico, 1998

[10] R. Duvigneau, M. Visonneau, Hybrid genetic algorithm and artificial neural network for complex design optimization in CFD, Int. J. Numer. Methods Fluids 44 (2000) $1255-1278$

[11] M. Sessaregoa, K.R. Dixonb, D.E. Rivala, D.H. Wood, A hybrid multi-objective evolutionary algorithm for windturbine blade optimization, Eng. Optim. (2014) available at: http://dx.doi.org/10.1080/0305215X.2014. 941532

[12] J.F. Manwell, J.G. McGowan, A.L. Rogers, Wind energy explained, New York, USA, John Wiley \& Sons Ltd, 2002

[13] D.M. Eggleston, F.S. Stoddard, Wind turbine engineering design, New York, USA, Van Nostrand Reinhoid, 1987

[14] D.J. Malcolm, A.C. Hansen, WindPACT turbine rotor design study, Subcontractor report, Golden: National Renewable Energy Laboratory, NREL/SR-500-32495, 2002, 82 p.

[15] D.J. Malcolm, A.C. Hansen, WindPACT turbine rotor design, specificrating study, Subcontractor report, Golden: National Renewable Energy Laboratory, NREL/SR-500-34794, 2003, 42 p.

[16] J.F. Manwell, J.G. McGowan, A.L. Rogers, Wind energy explained, Wiley Online Library, 2002

[17] E. Bossanyi, GH bladed theory manual, GH \& Partners Ltd., 2003

[18] J. H. Holland, Adaptation in Natural and Artificial Systems, The University of Michigan Press, Ann Arbor, Michigan, 1975
[19] D.T. Pham, A. Ghanbarzadeh, E. Koc, S. Otri, Application of the Bees Algorithm to the Training of Radial Basis Function Networks for Control Chart Pattern Recognition, 5th CIRP International Seminar on Intelligent Computation in Manufacturing Engineering (CIRP ICME '06). Ischia, Italy, July 25-28, 2006, pp. 711-716.

[20] A. Joodaki, A. Ashrafizadeh, A. Shadaram, Comparison of Continuous and Binary Genetic Algorithms in the Numerical Solution of Internal/External Shape Design Problems, An ECCOMAS Thematic Conference, CFD and Optimization, Turkey, 2011

[21] A. Lipowski, D. Lipowska, Roulette-wheel selection via stochastic acceptance, Physica A 391 (2012) 2193-2196

[22] D.E. Goldberg, K. Deb, A comprehensive analysis of selection schemes used in Genetic Algorithm, Foundation of Genetic Algorithms 1 (1991) 69-93

[23] P.C. Pendharkar, J.A. Rodger, An empirical study of impact of crossover operators on the performance of nonbinary genetic algorithm based nueral approaches for classification, Comput. Oper. Res. 31 (2004) 481-498

[24] D.T. Pham, A. Ghanbarzadeh, E. Koc, S. Otri, S. Rahim, M. Zaidi, Technical Note: Bees Algorithm, Manufacturing Engineering Centre, Cardiff University, Cardiff, Wales, 2005

[25] A. Muthiah, R. Ajkumar, A Comparison of Artificial Bee Colony algorithm and Genetic Algorithm to Minimize the Makespan for Job Shop Scheduling, Proc. Eng. 97 (2014) $1745-1754$

[26] R. Forsatia, A. Keikhab, M. Shamsfard, An improved bee colony optimization algorithm with an application to document clustering, Neurocomputing 159 (2015) 9-26

[27] H. Zarea, F. Moradi Kashkooli, A. Mansuri Mehryan, M.R. Saffarian, E. Namvar Beherghani, Optimal design of plate-fin heat exchangers by a Bees Algorithm, Appl. Thermal Eng. 69 (2014) 267-277

[28] M. Lozano, F. Herrera, J.R. Cano, Replacement strategies to preserve useful diversity in steady-state genetic algorithms, Inf. Sci. 178 (2008) 4421-4433

[29] G. Wang, L. Guo, A Novel Hybrid Bat Algorithm with Harmony Search for Global Numerical Optimization, Hindawi Publishing Corporation, J. Appl. Math. 2013, 21 p. Article ID 696491

[30] R. Poore, T. Lettenmaier, Alternative design study report: WindPACT advanced wind turbine drive train design study, Subcontractor report. Golden:National Renewable Energy Laboratory, NREL/SR-500-33196, 2003, 556 p.

[31] D.M. Somers, The S827 and S828 Airfoils. Subcontractor report. National Renewable Energy Laboratory, Golden, NREL/SR-500-36343, 2005, 54 p. 